\title{
Is multiple session of intralesional bleomycin mandatory for complete resolution of macrocystic lymphatic malformation?
}

\author{
Vijai Datta Upadhyaya, Ankur Bhatnagar', Basant Kumar, Zafar Neyaz², J. S. Kishore, \\ Eti Sthapak ${ }^{3}$ \\ Departments of Pediatric Surgery, ${ }^{1}$ Plastic Surgery and ${ }^{2}$ Radio Diagnosis, SGPGIMS, ${ }^{3}$ Department of Anatomy, RML, \\ PGIMER, Lucknow, Uttar Pradesh, India
}

Address for correspondence: Dr. Vijai Datta Upadhyaya, Department of Pediatric Surgery, SGPGIMS, Lucknow, Uttar Pradesh, India. E-mail: upadhyayavj@rediffmail.com

\section{ABSTRACT}

Background: Intralesional bleomycin scelro-therapy has become a favored line of treatment for macrocystic lymphatic malformations. However the need for multiple sessions is a drawback associated with this treatment modality. Our aim is to document whether multiple session of intra- lesional sclero-therapy is necessary for complete resolution of cystic lymphatic malformation. Method: Intralesional bleomycin under Ultrasound guidance was used for macrocystic lymphangioma at concentration of $3 \mathrm{mg} / \mathrm{ml}$ but not exceeding the total dose $(1 \mathrm{mg} / \mathrm{kg})$ body weight for single session or cumulative dose of $5 \mathrm{mg} / \mathrm{kg}$. In all cases intralesional sclerosant (ILS) was installed under proper aseptic precaution in operation theatre in general anesthesia or sedation depending on the site or size of lesion and age of the patient. Age of patients at the time of enrolment in study ranged from 3 months to 18 years. Clinical examination was the main stay of diagnosis which was supplemented by USG and/or computed tomography. Compression of the lesion site was done for few hours wherever it was possible after the ILS session. Result: A total of 21 patients included in our study. The age ranged from 3 months to 18 years. Male to female ratio was $8: 13$. The most common site of involvement was neck and axilla followed by anterior chest wall and nape of the neck. Complete resolution after single session was observed in $90.5 \%$ cases where as surgery was required in $9.5 \%$ case. Major complication was observed in one patient, who had intralesional bleeding which was managed conservatively. Transient pain and fever was observed in $23.8 \%$ of cases. Only two patient required surgical intervention where one had persistent subcutaneous fibrotic nodule and other one did not respond to ILS. Conclusion: Intralesional bleomycin is an effective treatment for macrocystic lesion, and complete resolution may be achieved by single session of ILS if proper principle are followed.

\section{KEY WORDS}

Cystic hygroma; intralesional bleomycin; sclerosant

\begin{tabular}{|l|l|}
\hline \multicolumn{2}{|c|}{ Access this article online } \\
\hline Quick Response Code: & Website: \\
\hline
\end{tabular}

This is an open access journal, and articles are distributed under the terms of the Creative Commons Attribution-NonCommercial-ShareAlike 4.0 License, which allows others to remix, tweak, and build upon the work non-commercially, as long as appropriate credit is given and the new creations are licensed under the identical terms.

For reprints contact: reprints@medknow.com

How to cite this article: Upadhyaya VD, Bhatnagar A, Kumar B, Neyaz Z, Kishore JS, Sthapak E. Is multiple session of intralesional bleomycin mandatory for complete resolution of macrocystic lymphatic malformation? Indian J Plast Surg 2018;51:60-5. 


\section{INTRODUCTION}

ixty per cent of all lymphatic malformations (LMs) are observed at birth. ${ }^{[1]}$ It is a benign lesion and needs attention mostly because of aesthetic reasons and complications such as compression of adjacent organs, leading to respiratory obstruction, dysphagia, nerve compression and malocclusion. LM can present with local inflammation, infection, sinus formation and haemorrhage. Spontaneous resolution is known but is very rare. Till recently, surgical excision was considered the treatment of choice. Surgery has a high rate of complication with chances of recurrences which are difficult to manage. ${ }^{[2]}$ Intralesional sclerotherapy (ILS) has been advocated as a popular alternative to surgery, mainly for superficial LM. The main drawback of ILS, cited in literature, is the need for multiple sessions to achieve an acceptable outcome as compared to surgical excision. ${ }^{[2]}$ Only a few sporadic case reports have shown complete resolution of LM with one session of ILS. ${ }^{[3]}$ This study was conducted with the aim to study whether multiple sessions of intralesional bleomycin are necessary for complete resolution of the lesion.

\section{MATERIALS AND METHODS}

Data of all the patients of macrocystic LM aged below 18 years presenting either in the Department of Paediatric Surgery or Plastic Surgery from January 2012 to December 2016 were analysed retrospectively. The patients with microcystic lesion with associated haemangiomatous component or macrocystic lesion having more than five cysts were excluded from the study (to avoid tackling a large number of cysts in one sitting). A total of 21 cases aged ranging from 3 months to 17 years were included. All possible complications such as infection or haemorrhage were recorded. Ultrasound (USG) was done in all cases to confirm the diagnosis and to characterize the lesion into micro- or macro-cystic lesions as per the latest classification. ${ }^{[1]}$ Post-procedure follow-up was done at 6 months using USG to document the size and volume of the residual lesion. All the parents had agreed with the proposed treatment and post-operative evaluation. ILS is the standard modality for the treatment of pure lymphatic or mixed LMs at our centre. All patients were strictly scrutinized for the presence of any lung pathology before initiation of therapy and were subjected to one shot of intravenous antibiotic before ILS and oral antibiotics for $72 \mathrm{~h}$ and analgesic for $48 \mathrm{~h}$ post-procedure.

\section{Treatment protocol for intralesional sclerotherapy}

All interventions were done under general anaesthesia/sedation in the operation theatre [Figure 1], and the lesion was localized on USG [Figure 2]. Individual cysts were punctured using 22 or $20 \mathrm{Fr}$ intravenous cannula under USG guidance. After puncture, metallic stellate of the cannula was used to monitor the exact placement of the cannula [Figure 3] in the cyst cavity. After confirming cannula placement, i.e., free flow of clear fluid, metallic stellate was withdrawn and the plastic cannula left in situ. The main objective of cyst aspiration was to completely evacuate the cyst for optimum action of the drug. With the aspirating cannula left in situ, bleomycin was injected under USG guidance taking care not to dislodge the cannula from the cyst cavity [Figure 4]. Drug delivery was confirmed into the cyst cavity with USG. Bleomycin was injected individually in each cyst, and care was taken that total dose should not exceed the recommended dose of $0.5 \mathrm{mg} / \mathrm{kg}^{\mid{ }^{\mid 3-5]}}$ Post-procedure, compression of the injection site (wherever it was possible) was done for $6 \mathrm{~h}$. Strict monitoring of the vitals was done up to $6 \mathrm{~h}$ post-procedure, and the patients were discharged within 24-48 h of the procedure.

\section{Evaluation and follow-up of lesion}

Patients were evaluated clinically at 3 and 6 months post-procedure [Figure 5]. Subsequently, all patients were reviewed at 6 monthly intervals for at least 2 years. USG evaluation of the residual lesion was done at the second visit, i.e., 6 months [Figure 6] post-procedure, and the size were compared with the previous scan (especially volume of the lesion). The patients were graded into complete resolution, incomplete resolution

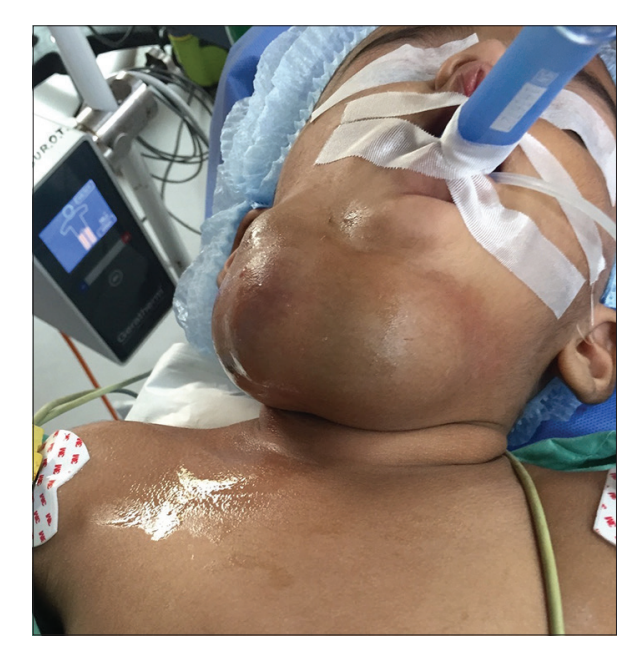

Figure 1: Large cystic hygroma involving neck before sclerotherapy under general anaesthesia 


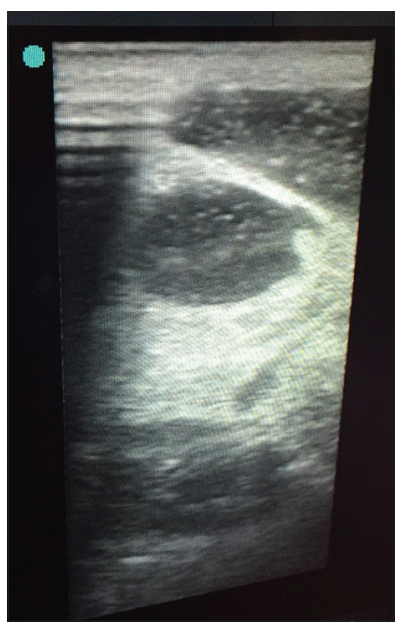

Figure 2: Ultrasound picture showing large cystic lesion before sclerotherapy

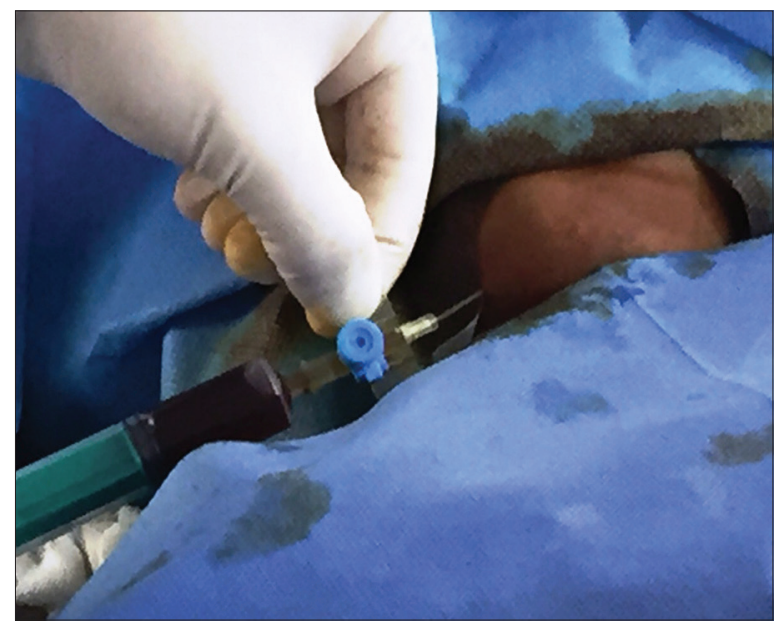

Figure 4: Aspiration of the content (haemorrhagic)

and failure as summarised in Table 1. Thus, our emphasis was on the cosmetic improvement of the lesion unlike the previous series where it was graded as excellent with more than $90 \%$ reduction in the size of lesion, good with $50 \%-90 \%$ reduction and poor in the rest of the cases. ${ }^{[3-5]}$

\section{RESULTS}

A total of 21 patients was included in our study. The age ranged from 3 months to 17 years. Male to female ratio was $8: 13$. The most common site of involvement was neck and axilla followed by anterior chest wall and nape of the neck. Complete resolution was observed in $91 \%$ of cases, none of our patients landed in the partial response group and surgical excision was done in two cases [Table 1]. Major complication in the form of intralesional bleeding was seen in one patient and managed conservatively. Transient pain and fever were observed in $23.8 \%$ of cases. Results are summarized in Table 2. Only two patients required surgical intervention where one had a persistent

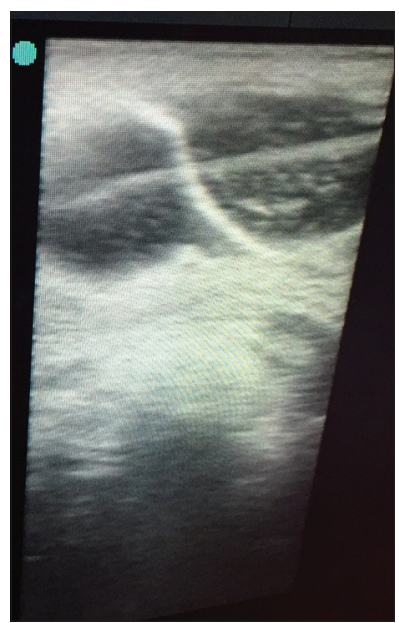

Figure 3: Ultrasound showing $20 \mathrm{Fr}$ intravenous cannula with metallic stent just before aspiration of the fluid note single cannula will be used for aspiration of both cysts

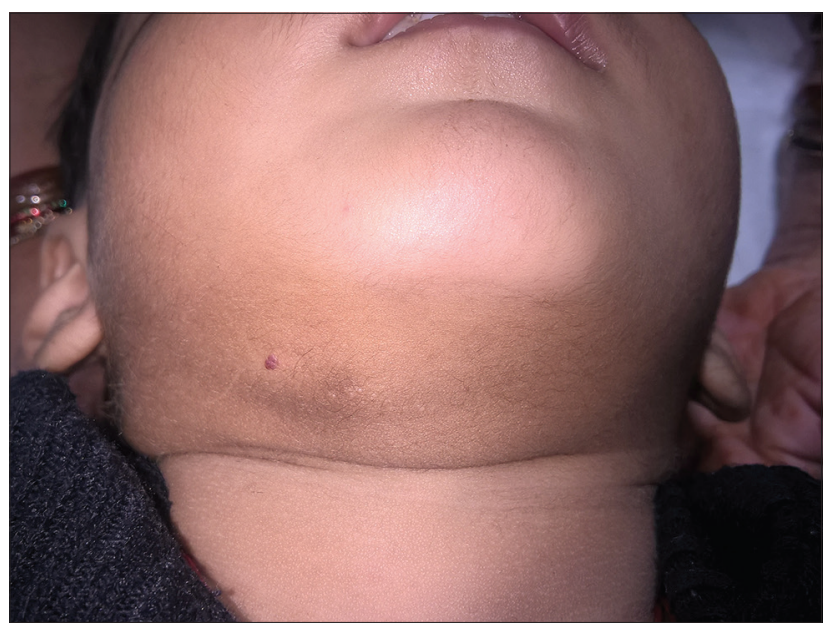

Figure 5: Follow-up picture of same patient at 3 months

Table 1: Response criteria

\begin{tabular}{ll}
\hline Response & Features \\
\hline $\begin{array}{l}\text { Complete } \\
\text { resolution }\end{array}$ & $\begin{array}{l}\text { No residual mass or }<10 \% \text { of residual lesion } \\
\text { (in comparison to first ultrasound) in the form of } \\
\text { cyst or fibrotic lesion on ultrasound and not evident } \\
\text { clinically. (19 cases) }\end{array}$ \\
$\begin{array}{l}\text { Incomplete } \\
\text { resolution }\end{array}$ & $\begin{array}{l}\text { More than } 10 \% \text { but }<30 \% \text { of residual lesion on } \\
\text { ultrasound (in comparison to first ultrasound) or } \\
\text { residual mass evident on careful examination. } \\
\text { (no cases) }\end{array}$ \\
Failure & $\begin{array}{l}\text { Residual lesion of more than } 30 \% \text { of initial size or } \\
\text { a lesion apparently evident on clinical examination } \\
\text { (2 cases) }\end{array}$ \\
\hline
\end{tabular}

subcutaneous fibrotic nodule and another one did not respond to intra lesional bleomycin ILS.

\section{DISCUSSION}

Recent classifications have extended the range of LMs and have included various generalised lymphatic 
Table 2: Clinical response and complication

\begin{tabular}{lclll}
\hline $\begin{array}{l}\text { Number of } \\
\text { cysts } \text { in lesion }\end{array}$ & $\begin{array}{l}\text { Number } \\
\text { of cases }\end{array}$ & Number of sessions & Complications & Result \\
\hline 1 cysts & 3 & Single session & F-2, P-1 & CR after 1 session - all 3 cases \\
$2-3$ cysts & 16 & $\begin{array}{l}\text { In two cases, two sessions, and in } \\
\text { rest, 14 single session }\end{array}$ & F-3, P-2, B*-1 & CR after 2 session - 12 cases \\
& & & & CR after 2 sessions - 2 cases \\
& 2 & Ningle session -2
\end{tabular}

B: Post-procedure bleeding ( ${ }^{*}$ This patient developed large fibrotic mass after the first session and was not amenable for the second session of bleomycin and required surgical excision). CR: Complete response (where resolution is more than $90 \%$ of initial size on ultrasound and no obvious clinical lesion appreciable), PR: Poor response (where residual lesion is more than $20 \%$ and not amenable to further sclerotherapy or not responding after the second session), F: Fever requiring antipyretic, P: Post-procedural pain requiring analgesic, NR: No Response

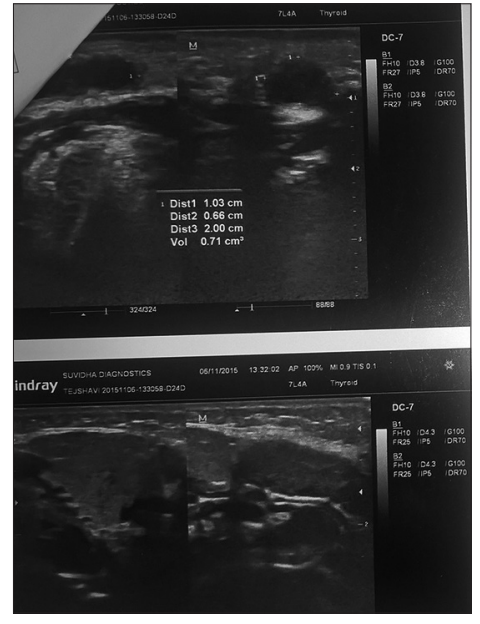

Figure 6: Repeat ultrasound showing very small residual (not amenable to aspiration) lesion after 6 months of the first session

disorders under one umbrella. ${ }^{[1]}$ Moreover, the arbitrary distinction of macrocystic and microcystic malformation on the size of the cyst has been done away with. Cysts which can be successfully aspirated or sclerosed resulting in the decrease in size of lesion are considered significant or macrocysts. ${ }^{[6]}$ Usually, macrocysts respond well to sclerotherapy whereas microcystic lesion requires surgical intervention.

The best diagnostic tool to differentiate LMs from cystic lesions of the neck is magnetic resonance imaging, but USG can usually confirm and differentiate cystic LM from other cystic lesion. ${ }^{[7]}$

LMs are benign lesions but warrant urgent attention because of its potential complications such as intralesional bleeding and infections. In the present series, three patients had features of secondary infection at the time of the first presentation, but all responded to the conservative treatment. Another reason for sudden enlargement of the lesion is spontaneous bleeding, which usually responds to conservative management but may need emergency surgery. ${ }^{[8,9]}$ In the present series, only one patient presented with spontaneous bleeding and was managed conservatively. None of our patients presented with post-procedural infection although one presented with intralesional bleeding after the procedure. This patient was initially managed conservatively but developed a subcutaneous fibrotic mass which required surgical excision. Surgical excision of post-sclerotherapy lesion is difficult due to dense adhesion between residual cyst and neighbouring tissue, leading to loss of tissue plane.

Surgical excision is the standard treatment for LM; however, due to the proximity of the lesion with nerve and important vessels, sometimes, complete excision is not possible which may lead to recurrence. The recurrence rate after surgery may be as high as $27 \%$ in some series with a mortality of around $2 \% .^{[2,10]}$ Other post-operative complications observed after surgical excision of LM are wound infection, haemorrhage, scar hypertrophy and persistent lymphorrhea and lymphangioma circumscriptum. These limitations of surgical intervention led to an interest in alternative treatment options such as ILS. ${ }^{[1]}$

ILS has many benefits over surgical approach such as less chances of recurrence, no or minimal scar, minimal chances of nerve or vascular injury. Several sclerosing agents, such as ethanol, sodium tetradecyl sulphate and doxycycline, have been used in LMs; however, two most extensively used sclerosants are bleomycin and OK432; [12-14] because of easy availability and low cost, we used bleomycin in our study.

In multicystic lesions, especially with more than five cysts, it was observed that the individual cysts were very small; hence, it was not possible to target each cyst individually in one sitting, and dose of bleomycin may exceed the upper limit $(0.5 \mathrm{ml} / \mathrm{kg})$. Keeping the maximal dose concern in our mind, we have restricted this study to multicystic lesions having $<5$ cysts on USG evaluation. 
Most of the published series reported complete resolution in $60 \%$ of cases with marked reduction in size in $>30 \%$ cases after 3-6 sessions of bleomycin ILS. ${ }^{[1]]}$ In the present series, $85 \%$ of cases had almost complete resolution or had small residual fibrotic mass which was clinically not appreciable after a single session of ILS, and $90.5 \%$ had complete resolution after the second session whereas, around 9.5\% ( 2 cases) required surgical excision.

It was observed that the patients who did not have a history of previous infection or bleeding in the cyst had better response with no residual fibrotic lesion in comparison to the lesions that had one or more complication before ILS initiation. The possible reasons for better results in our series are as follows: In all cases, cysts were tackled individually under strict aseptic precaution in operation theatre. The cyst content was completely aspirated under the USG guidance before instillation of bleomycin, thus decreasing the chances of dilution of the drug and increasing the contact of bleomycin with the endothelial lining of the cyst. The intimate contact between the bleomycin solution and cyst endothelial lining post-aspiration, we feel, is the most important aspect of the treatment. We believe that the intense inflammation caused by bleomycin solution leads to the loss of secretory power of the endothelial lining and extensive post-inflammatory fibrosis. Second, the concentration of bleomycin $(3 \mathrm{mg} / \mathrm{ml}$ of dilution) used in our series led to more intense fibrosis as reflected as better result in our series; however, in none of the patients, total dose did not exceed $0.5 \mathrm{mg} / \mathrm{kg}$ body weight. Third, in our series, the proposed interval between the two sessions was 6 months or more unlike most of the reported series where duration between two sessions was $4-8$ weeks, and we think that it may be the desired time for optimal action and effect of the drug. Finally, post-therapy compression decreased the chances of seroma formation as well as increased the contact time between bleomycin solution and cyst endothelial lining.

This mode of treatment is not free of complication, but the severity and frequency of complication are much less when compared with surgery. The reported complications of sclerotherapy with bleomycin are discolouration of the injection site, sudden increase in the size of LM, fever, vomiting, cellulitis, interstitial pneumonia and pulmonary fibrosis. Pulmonary fibrosis is associated with high dosage of bleomycin. ${ }^{.15]}$ The safe upper limit dose of bleomycin in single session is $0.5 \mathrm{ml} / \mathrm{kg}$ body weight, but it ranges from 0.3 to $1 \mathrm{mg} / \mathrm{kg}^{[16]}$ and upper limit of cumulative dose is $5 \mathrm{mg} / \mathrm{kg} \cdot{ }^{[17]}$ In our series, none of the patients had pulmonary fibrosis (though still long time follow is required to rule out pulmonary fibrosis); because the total dose of drug used was very small, $21 \%$ of cases developed high-grade fever which subsided with antibiotic and antipyretic within 3 days, and the pain was complained by $18 \%$ cases which was resolved with oral analgesic.

\section{CONCLUSION}

We believe that intralesional bleomycin sclerotherapy can be a safe and first-line therapy for macrocystic LM in children and feel that even large macrocystic LMs can be treated in a single sitting if done adequately.

\section{Declaration of patient consent}

The authors certify that they have obtained all appropriate patient consent forms. In the form the patient(s) has/have given his/her/their consent for his/her/their images and other clinical information to be reported in the journal. The patients understand that their names and initials will not be published and due efforts will be made to conceal their identity, but anonymity cannot be guaranteed.

\section{Financial support and sponsorship}

Nil.

\section{Conflicts of interest}

There are no conflicts of interest.

\section{REFERENCES}

1. Wassef M, Blei F, Adams D, Alomari A, Baselga E, Berenstein A, et al. Vascular anomalies classification: Recommendations from the international society for the study of vascular anomalies. Pediatrics 2015;136:e203-14.

2. Acevedo JL, Shah RK, Brietzke SE. Nonsurgical therapies for lymphangiomas: A systematic review. Otolaryngol Head Neck Surg 2008;138:418-24.

3. Sharif M, Elsiddig IE, Atwan F. Complete resolution of cystic hygroma with single session of intralesional bleomycin. J Neonatal Surg 2012;1:44.

4. Olímpio Hde O, Bustorff-Silva J, Oliveira Filho AG, Araujo KC. Cross-sectional study comparing different therapeutic modalities for cystic lymphangiomas in children. Clinics (Sao Paulo) 2014;69:505-8.

5. Lee BB, Laredo J, Lee TS, Huh S, Neville R. Terminology and classification of congenital vascular malformations. Phlebology 2007;22:249-52.

6. Mirza B, ljaz L, Saleem M, Sharif M, Sheikh A. Cystic hygroma: An overview. J Cutan Aesthet Surg 2010;3:139-447.

7. Mathur NN, Rana I, Bothra R, Dhawan R, Kathuria G, Pradhan T, et al. Bleomycin sclerotherapy in congenital lymphatic and vascular malformations of head and neck. Int $\mathrm{J}$ Pediatr 
Otorhinolaryngol 2005;69:75-80.

8. Dhrif AS, El Euch D, Daghfous M, Cherif F, Mokni M, Dhahri AB. Macrocystic lymphatic lymphangioma (cystic lymphangioma) of upper extremity: A case report. Arch Pediatr 2008;15:1416-9.

9. Rattan KN, Kajal P, Kadian YS, Gupta R. Haemorrhage in a scrotal lymphangioma in a child: A rarity. Afr J Paediatr Surg 2009;6:110-1.

10. Ameh EA, Nmadu PT. Cervical cystic hygroma: Pre-, intra-, and post-operative morbidity and mortality in Zaria, Nigeria. Pediatr Surg Int 2001;17:342-3.

11. Niramis R, Watanatittan S, Rattanasuwan T. Treatment of cystic hygroma by intralesional bleomycin injection: Experience in 70 patients. Eur J Pediatr Surg 2010;20:178-82.

12. Horbach SE, Rigter IM, Smitt JH, Reekers JA, Spuls PI, van der Horst $\mathrm{CM}$, et al. Intralesional bleomycin injections for vascular malformations: A Systematic review and meta-analysis. Plast Reconstr Surg 2016;137:244-56.
13. Zhang W, Chen G, Ren JG, Zhao YF. Bleomycin induces endothelial mesenchymal transition through activation of mTOR pathway: A possible mechanism contributing to the sclerotherapy of venous malformations. Br J Pharmacol 2013;170:1210-20.

14. Hashimoto N, Phan SH, Imaizumi K, Matsuo M, Nakashima H, Kawabe $\mathrm{T}$, et al. Endothelial-mesenchymal transition in bleomycin-induced pulmonary fibrosis. Am J Respir Cell Mol Biol 2010;43:161-72.

15. XuDP, Zhai QK, Cheng C, Gong H, Wang HW, Wang XK, etal. Appraisal of efficacy and safety of intralesional injection of high concentration of bleomycin A5 for treatment of huge macrocystic lymphatic malformations in cervical region. J Craniofac Surg 2014;25:1707-9.

16. Jain V, Mohta A, Sengar M, Bansal K, Valvi K. Use of intralesional bleomycin as primary therapy in macrocystic lymphangiomas. Indian J Dermatol Venereol Leprol 2013;79:524-5.

17. Shankar VN, Ashwini NS, Praveena V. Lymphvasculogenesis and lymphangioma - An update. J Cancer Sci Ther 2011;3:5. 